\title{
Efeito dos óleos vegetais de andiroba (Carapa sp.) e Copaíba (Copaifera sp.) sobre forídeo, pragas de colméias, (Diptera: Phoridae) na Amazônia Central
}

\author{
Delci da Costa Brito FREIRE ${ }^{1}$; Carmina Rodrigues da Costa BRITO-FILHA ${ }^{1}$; \\ Gislene Almeida CARVALHO-ZILSE²
}

\section{RESUMO}

O conhecimento de substâncias repelentes para forídeos é um passo importante para a meliponicultura brasileira, pois esses insetos podem causar sérios danos às colméias de abelhas nativas. Os óleos de copaíba e andiroba, naturalmente encontrados na região amazônica, são muito utilizados pelos povos tradicionais da região como repelentes de insetos. Foi observado o efeito de dois óleos vegetais (andiroba e copaíba) sobre a postura de ovos por fêmeas de forídeos em condições de laboratório. A postura das fêmeas foi realizada preferencialmente no substrato pólen e diferiu estatisticamente dos substratos contendo óleo de andiroba ou copaíba, nos quais houve considerável diminuição (até nenhuma postura), e do substrato contendo mel. Esses óleos são uma boa alternativa no controle preventivo e curativo dessa praga em colônias de Meliponineos, devido ao seu efeito repelente, ao baixo custo e disponibilidade na Região Amazônica.

\section{PALAVRAS-CHAVE}

Carapa, Copaifera, Repelente natural, Phoridae, Abelha sem ferrão.

\section{Effect of andiroba (Carapa sp.) and copaiba's (Copaifera sp.) vegetable oils on phorides, hives's prague (Diptera: Phoridae) in Central Amazonia}

\begin{abstract}
The knowlegment of repellants substances to phoride flies is an important step to the Brazilian stinglessbee beekeeping due to the serious damage to the native bee hives they can do. The copaiba and andiroba oils, found commonly in the Amazon region, are very employed by the traditional people as insects' repellants. We observed the effect of these oils over the phoride's laying in laboratory conditions. The female phoride's eggs occurred preferentially in the pollen substrate and statistically differed from those containing andiroba and copaiba oils, which was strongly reduced (until none eggs were laid), and from the substrate containing honey. These oils showed to be quite good alternative for this plague's preventive and curative control in stingless bee hives due to its repellant effect, low cost, and availability to get it in the region.
\end{abstract}

\section{KEY WORDS}

Carapa, Copaifera, Natural repelent, Phoridae, Stingless bee.

1E-mail: del7freire@gmail.com, Secretaria Municipal de Educação, Gerência Distrital Zona Rural. Rua Rio Içá 850, Vieiralves, Manaus, Amazonas, Brasil;

${ }^{2}$ Grupo de Pesquisas em Abelhas, Coordenação de Pesquisas em Ciências Agronômicas, Instituto Nacional de Pesquisas da Amazônia. Av. André Araújo 2936, Cx. Postal 478, CEP 69083-000, Manaus, Amazonas, Brasil. 


\section{INTRODUÇÃO}

A família Phoridae (Insecta: Diptera) possui cerca de 3.000 espécies, apresentando maior diversidade nos trópicos (Brown, 1995). Estes dípteros variam de 1 a $2 \mathrm{~mm}$ de tamanho, sendo facilmente reconhecidos pelo aspecto curvado e venação característica da asa com fortes veias longitudinais, cabeça pequena e coloração geralmente escura (Disney, 1994).

As larvas apresentam hábitos variados, ocorrendo na matéria em decomposição, fungos e parasitando ninhos de formigas (Feener \& Brown, 1993; Embrapa, 2001), abelhas (Borgmeier, 1925, 1934; Nogueira-Neto, 1970; Portugal-Araújo, 1977; Kerr, 1996; Kerr et al., 1996) e cupins (Disney, 1994).

No Brasil, os forídeos causam grandes prejuízos à criação racional das abelhas indígenas sem ferrão, atividade denominada meliponicultura. De acordo com Nogueira-Neto (1953, 1970 e 1997) há quatro gêneros de forídeos que freqüentam as colônias de Meliponini: Pseudohypocera, Megaselia (Aphiochaeta), Melitophora e Melaloncha. A espécie Pseudohypocera kerteszi Enderlein, 1912, é citada como uma das principais inimigas dessas abelhas e também dos gêneros Trigona e Apis (Reyes, 1983).

Mesmo os forídeos sendo os principais causadores de danos para a criação de abelhas do Norte ao Sul do Brasil, estes indivíduos não são encontrados na Baixada Maranhense (São Luis) (Kerr, 1996) e em algumas épocas do ano desaparecem das colméias. E, na Amazônia pode se transformar em praga, principalmente no período das chuvas, aliado à falta de manejo adequado por parte dos criadores dessas abelhas (Portugal-Araújo, 1977).

O forídeo adulto praticamente não produz danos diretamente aos Meliponíneos, mas no estágio larval são comedores vorazes de pólen, podendo inclusive destruir os discos (ou favos em Apis) de cria e exterminar uma colônia, caso a infestação seja muito forte (Nogueira-Neto, 1997).

Considerando o grande potencial das abelhas do gênero Melipona Illiger, 1806, em relação à produção de mel e pólen para a subsistência, ou mesmo a produção em grande escala, a incidência do ataque de larvas de forídeos nestas abelhas acarreta perda de produção e conseqüente prejuízo para o produtor (Kerr et al., 1996).

O conhecimento de substâncias repelentes para forídeos, para impedir a infestação de colônias de abelhas, é um passo importante para os estudos que visem à proteção das colônias, como é o caso das propriedades encontradas nos óleos de copaíba e andiroba. Estes óleos, como produtos da natureza, são muito utilizados pelos povos tradicionais na Região Amazônica.

O óleo de copaíba é extraído do tronco de Copaifera sp. (Leguminosae), planta de ocorrência comum na floresta Amazônica (Ribeiro et al., 1999). Essa espécie vegetal é rica em diterpenóides, que são substâncias utilizadas como bálsamos (Veiga et al., 1997; Braga et al., 1998; Monti et al., 1999). Na medicina popular este óleo é utilizado como antiinflamatório, bactericida, diurético e expectorante e, sua madeira possui uma demanda maior devida a sua qualidade de repelir os insetos (Curupira, 2002).

O óleo de andiroba, Carapa sp. (Meliaceae) também é utilizado como repelente de insetos e apresenta propriedade antiinflamatória (Ribeiro et al., 1999). De acordo com Pinto (1963) algumas tribos indígenas e determinadas comunidades tradicionais vêm usando o óleo de andiroba como repelente de insetos. A Fundação Osvaldo Cruz desenvolveu e colocou no mercado a vela de andiroba para ser usada no combate de mosquitos que transmitem a dengue e a malária (Ferraz et al., 2002).

Neste sentido, este trabalho teve como objetivo verificar a influência desses óleos como repelentes naturais para os forídeos, em condições de laboratório como alternativa de controle da infestação natural em colônias de abelhas Melipona compressipes manaosensis Schwarz, 1932.

\section{MATERIAIS E MÉTODOS}

O presente trabalho foi conduzido no Laboratório do Grupo de Pesquisas em Abelhas - GPA (Coordenação de Pesquisas em Ciências Agronômicas - CPCA, Instituto Nacional de Pesquisas da Amazônia - INPA) por um período de 22 meses não consecutivos, entre os anos de 2002 a 2004.

Foram coletados indivíduos adultos de forídeos presentes em colméias de $M$. compressipes manaosensis infestadas naturalmente. Estes exemplares foram mantidos em caixa de madeira $(15 \times 15 \times 4 \mathrm{~cm})$ forrada com papel sulfite branco e tampada com filme plástico PVC com pequenos furos suficientes para permitir a ventilação, mas evitar a fuga de forídeos. A caixa foi mantida em laboratório, à temperatura ambiente, onde foram monitoradas até a morte desses indivíduos.

Os experimentos consistiram em monitorar, em cada caixa, a postura das fêmeas de forídeos sobre diferentes substratos disponíveis simultaneamente em potes plásticos recobertos com cera de abelha. Foram utilizadas seis caixas (repetiçôes) para cada tipo de óleo (andiroba e copaíba). Em cada caixa foram oferecidos três substratos, sendo: a) pote contendo pólen (diluído em água $3: 1$ ), b) pote contendo mel e c) pote contendo pólen misturado a óleo de andiroba ou óleo de copaíba $(60 \mathrm{~mL})$ (Figura 1). O pólen e mel utilizados foram retirados de colônias de Melipona seminigra merrillae Cockerell, 1919 do meliponário GPA.

As caixas foram monitoradas diariamente até a morte das fêmeas, sendo, em seguida, realizada a contagem das posturas por substrato.

\section{RESULTADOS E DISCUSSÃO}

Foi constatado que a duração média de vida das fêmeas adultas dos forídeos foi de 13 dias. 
Foi observado que as fêmeas de forídeos realizaram postura em todos os tipos de substratos (Tabelas 1 e 2). Ao nível de 5\% de probabilidade, pelo teste de Tukey, a quantidade de postura realizada nos substratos mel $(\mathrm{M})$, pólen com copaíba $(\mathrm{P}+\mathrm{C})$ e pólen com andiroba $(\mathrm{P}+\mathrm{A})$ não diferiram entre si e os mesmos diferiram do substrato pólen (P), indicando que o substrato pólen foi preferencialmente utilizado para oviposiçãa.

Entretanto, numa ocasião em que o pólen ressecou, as fêmeas de forídeos realizaram a oviposição nos potes com mel, e entre o filme plástico e a borda da caixa. Em ambos os casos os ovos não eclodiram, mas mesmo assim as fêmeas não utilizaram o pote com pólen misturado com andiroba para a postura. Em outra repetição, situação em que o pote com pólen ficou sem espaço para postura, devido ao grande número de larvas e ovos, as fêmeas

Tabela 1 - Número de posturas realizadas pelas fêmeas de forídeos nos substratos pólen, mel e pólen misturado a óleo de andiroba em caixas experimentais do Laboratório do Grupo de Pesquisas em Abelhas (GPA) INPA), Manaus - AM

\begin{tabular}{cccc}
\hline & \multicolumn{3}{c}{ Número de posturas realizadas } \\
\cline { 2 - 4 } Repetições & $\mathbf{P}$ & $\mathbf{M}$ & $\mathbf{P + A}$ \\
\hline Caixa 1 & 293 & 40 & $\mathbf{0}$ \\
Caixa 2 & 210 & 0 & 0 \\
Caixa 3 & 125 & 6 & 0 \\
Caixa 4 & 100 & 1 & 0 \\
Caixa 5 & 495 & 10 & 8 \\
Caixa 6 & 11 & 0 & 0 \\
Total & $\mathbf{1 2 3 4}$ & $\mathbf{5 7}$ & $\mathbf{8}$ \\
Porcentagem & $94,99 \%$ & $4,38 \%$ & $0,61 \%$ \\
\hline Média/Desvio padrão & $1234 \pm 171,42$ & $57 \pm 15,46$ & $8 \pm 3,26$ \\
\hline
\end{tabular}

$\mathbf{P}=$ pote contendo pólen; $\mathbf{M}=$ pote contendo mel; $\mathbf{P}+\mathbf{A}=$ pote contendo pólen misturado a óleo de andiroba

Tabela 2: Número de posturas realizadas pelas fêmeas de forídeos nos substratos pólen, mel e pólen misturado a óleo de copaíba, em caixas experimentais do Laboratório do Grupo de Pesquisas em Abelhas (GPA/ INPA), Manaus - AM

\begin{tabular}{cccc}
\hline & \multicolumn{4}{c}{ Número de posturas realizadas } \\
\cline { 2 - 4 } Repetições & $\mathbf{P}$ & $\mathbf{M}$ & $\mathbf{P + C}$ \\
\hline Caixa 1 & 280 & 0 & $\mathbf{0}$ \\
Caixa 2 & 251 & 5 & 48 \\
\hline Caixa 3 & 28 & 24 & 0 \\
Caixa 4 & 50 & 0 & 0 \\
\hline Caixa 5 & 470 & 30 & 1 \\
Caixa 6 & 69 & 0 & 0 \\
\hline Total & $\mathbf{1 1 4 8}$ & $\mathbf{5 9}$ & $\mathbf{4 9}$ \\
\hline Porcentagem & $91,40 \%$ & $4,69 \%$ & $3,90 \%$ \\
\hline Média/Desvio padrão & $191,33 \pm 173,61$ & $9,83 \pm 13,57$ & $8,17 \pm 19,52$ \\
\hline
\end{tabular}

$\mathbf{P}=$ pote contendo pólen; $\mathbf{M}=$ pote contendo mel; $\mathbf{P}+\mathbf{C}=$ pote contendo pólen misturado a óleo de copaíba

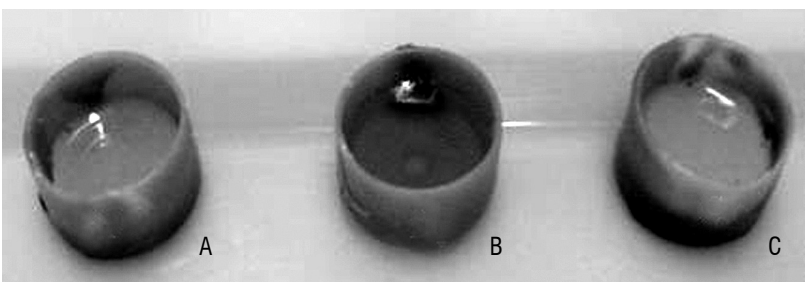

Figura 1 - Três diferentes substratos oferecidos simultaneamente para postura dos forídeos: A) pólen com óleo de andiroba ou de copaíba; B) mel e C) pólen diluído em água (3:1). Foto: Delci da Costa Brito Freire, 2004.

continuaram a postura no pote com pólen misturado à copaíba, porém, a fizeram apenas nas bordas e por fora do pote.

Os ovos colocados sobre o substrato contendo pólen eclodiram normalmente e as larvas se deslocaram pela caixa, entraram nos potes e se alimentaram de pólen misturado aos óleos. No caso dos indivíduos adultos, estes evitavam o contato com as substâncias oleosas, e as fêmeas fizeram pouquíssimas posturas nos potes que continham andiroba ou copaíba.

O substrato pólen misturado aos óleos de andiroba $(\mathrm{P}+\mathrm{A})$ ou copaíba $(\mathrm{P}+\mathrm{C})$ apresentaram menor número de ovos em ambos os experimentos chegando a nenhuma postura realizada na maioria das repetições. Apesar de não diferirem estatisticamente do substrato mel é possível justificar a menor quantidade de ovos postos nestes substratos baseado na ação repelente desses óleos sobre insetos e no comportamento observado durante a realização das posturas pelas fêmeas (postura pelo lado externo dos potes contendo os óleos).

A partir destes resultados, os óleos de andiroba e copaíba foram testados em 25 colônias de abelhas $M$. compressipes manaosensis alojadas no meliponário do GPA/INPA que estavam naturalmente infestadas com forídeos. A infestação foi constatada pela abertura das colméias e imediata revoada de diversos forídeos adultos pela tampa das caixas e também pela presença de ovos e larvas nos potes de pólen. Com auxilio de papel absorvente, uma fina camada dos óleos foi passada nas paredes internas da lixeira e da tampa destas colméias assim como ao redor do orifício de entrada (Figura 2). Verificou-se que após três dias não mais foi verificada a presença de forideos adultos nem de larvas indicando a ação repelente dos óleos. Não foi observada nenhuma alteração no desenvolvimento das abelhas das colônias tratadas neste experimento.

Os resultados repelente dos óleos de copaíba e andiroba demonstraram ser boa alternativa para combater as infestações dos indivíduos adultos de forídeos, quando utilizados nas superfícies das colméias (tampa, lixeira e orifício de entrada) conforme observado em Melipona compressipes manaosensis.

Ainda assim, se recomenda a retirada de ovos, larvas e pupas de forídeos presentes nas colônias conjuntamente com o uso dos óleos (andiroba ou copaíba). 


\section{CONCLUSÕES}

Em condições de laboratório, o substrato pólen foi preferencialmente utilizado para realização das posturas por fêmeas de forídeos em contraste com os substratos óleo de andiroba ou de copaíba misturado ao pólen que demonstraram efeito repelente, na maioria das repetições, levando a inibição de até $100 \%$ da postura.

Os óleos de andiroba ou copaíba podem ser utilizados como tratamento para colônias infestadas por forídeos ou ainda como preventivo antes que haja uma infestação. Vale ressaltar que para o sucesso destes óleos como repelente sobre os forídeos é necessário que se tenha certeza da procedência dos mesmos para se garantir que não estejam misturados a outras substâncias, alterando assim sua composição química e conseqüente perda de suas propriedades, ou mesmo, levando à intoxicação as abelhas e morte da colônia.

\section{AGRADECIMENTOS}

Ao Dr. Warwick E. Kerr pelas sugestōes e incentivo. A MSc. Cristiane Dias pelas primeiras sugestōes bibliográficas. Ao MSc. Carlos Gustavo Nunes pela tradução do abstract. A Dra. Suely Costa pelas análises estatísticas. E a todos os colegas de trabalho do GPA pelas amostras de forídeo. Ao CNPq pela bolsa PIBIC e auxilio financeiro, a SUFRAMA e FAPEAM pelo auxilio financeiro.

\section{BIBLIOGRAFIA CITADA}

Borgmeier, O. F. M. 1925. Novos subsídios para o conhecimento da Família Phoridae (Diptera). Arquivos do Museu Nacional do Rio de Janeiro, 25:85-281.

Borgmeier, O. F. M. 1934. O gênero Melaloncha Brués (Díptera: Phoridae). Review Entomological, 4:167-189.

Braga, W. F.; Rezende, C. M.; Antunes, O. A. C. 1998. Terpenoids from Copaiba cearensis. Phytochemistry, 49(1):263-264.

Brown, B. V. 1995. Review of "Scuttle flies": The Phoridae. Bulletin Entomological Society of Canada, 27:41-42.

Curupira. 2002. Óleos de Copaíba. Disponível no site: www.curupira.com.br/produtos/oleo_copaiba.htm. Acessado em: 24/05/2002.

Disney, R. H. L. 1994. Scuttle flies: The Phoridae. London: Chapman and Hall. 467pp.

Embrapa. 2001. Mosca brasileira salva lavoura nos EUA. Informativo do Centro Nacional de Pesquisa de Monitoramento e Avaliação de Impacto Ambiental, no 34, 5pp.
Feener, D. H. Jr.; Brown, B. V. 1993. Oviposition behavior of an ant-parasitizing fly, Neodohrniphora curvinervis (Diptera: Phoridae), and defense behavior by its leaf-cutting and host Atta cephaletes (Hymenoptera: Formicidae). Journal Insect Behaviour, 6:675-688.

Ferraz, I. D. K.; Camargo, J. L. C.; Sampaio, P. T. B. 2002. Sementes e Plântulas de Andiroba (Carapa guianensis AUBL. e Carapa procera D.C.): Aspectos Botânicos, Ecológicos e Tecnológicos. Acta Amazonica, 32(4):647-661.

Kerr, W. E. 1996. Biologia e Manejo da tiúba: a abelha do Maranhão. EDUFMA. São Luís, MA. 156pp.

Kerr, W. E.; Carvalho, G. A. e Nascimento, V. A. 1996. Abelha Uruçu: Biologia, Manejo e Conservação. Ed. Fundação Acangau, Paracatu, MG. 144pp.

Monti, H.; Tiliacos, N.; Faure, R. 1999. Copaiba oil: isolation and characterization of a new diterpenoid with the dinorlabdane skeleton. Phytochemistry, 51(8):1013-1015.

Nogueira-Neto, P. 1953. A criação de Abelhas Indígenas sem Ferrão. São Paulo: Chácaras e Quintais, 280pp.

Nogueira-Neto, P. 1970. Vida e Criação de Abelhas Indígenas Sem Ferrão. São Paulo, Nogueirapis. 365pp.

Nogueira-Neto, P. 1997. Vida e Criação de Abelhas Indígenas Sem Ferrão. São Paulo, Nogueirapis. 445pp.

Pinto, P. G. 1963. Características físico-químicas e outras informações sobre as principais oleaginosas do Brasil - Boletim Técnico 18, Ministério da Agricultura, Recife/ PE, Brasil.

Portugal-Araujo, V. 1977. Contribuição para o conhecimento da biologia de Pseudohypocera kerteszi (Enderlein, 1912), seu acasalamento e captura (Diptera, Phoridae). Acta Amazonica, 7(2):153-155.

Reyes, F.O. 1983. A new record of Pseudohypocera kerteszi, a pest of bees in Mexico. American Bee Journal, 123(2):119-120.

Ribeiro, J.E.L.S.; Hopkins, M.J.G.; Vicentine, A.; Sothers, C.A.; Costa, M.A.S.; Brito, J.M.; Souza, M.A.D.; Martins, L.H.P.; Lohmann, L.G.; Assunção, P.A.C.L.; Pereira, E.C.; Silva, C.F.; Mesquita, M.R.; Procópio, L.C. 1999. Flora da Reserva Ducke: Guia de identificação das plantas vasculares de uma floresta de terra firme na Amazônia Central. INPA, Manaus, Amazonas. 816 pp.

Veiga, V. F.; Patitucci, M. L.; Pinto, A. C. 1997. Autenticity control of commercial copaiba oils by high resolution gas chromatography. Quimica Nova, 20(6):612-615.

Recebido em 02/05/2005

Aceito em 12/06/2006 